DOI: 10.12957/demetra.2015.16055

\title{
Alimentação em conflito: o comer em tempos de crise em Persépolis
}

\section{Feeding in conflict: eating in times of crisis in Persepodis}

\author{
Victória Cândido Bertoldo \\ Michelle Medeiros' \\ Viviany Moura Chaves' \\ Poliana de Araújo Palmeira' \\ 1 Universidade Federal de Campina Grande, \\ Departamento de graduação em Nutrição. \\ Cuité-PB, Brasil. \\ Correspondência / Correspondence \\ Michelle Medeiros \\ E-mail:mcmedeiross@gmail.com
}

\section{Resumo}

O objetivo deste artigo é compreender as alterações que conflitos políticos apresentados na obra Persépolis, utilizada como corpus desta pesquisa, geram no espaço social alimentar. Por se tratar de um diário ilustrado, do tipo de história em quadrinhos, de caráter autobiográfico, na obra foram utilizados dois tipos de análises, verbais e de imagens, que tiveram tratamentos de dados específicos, enfocando trechos que abordam o tema "Alimentação" em relação ao cenário de conflitos gerados pela revolução iraniana. Os dados verbais foram recortados em quadros sequenciais e neles foram observados elementos de interesse para a pesquisa. Quanto aos dados visuais, foi observada a presença de objetos, expressões faciais e corporais dos personagens. Em ambas as abordagens, buscaram-se dados em que o tema do Espaço Social Alimentar vigente se explicitasse. Foi elaborada uma matriz de classificação. A análise retornou os seguintes dados: (1) há no cenário de Persépolis a produção de uma fome epidêmica; (2) o conflito impõe aos sujeitos uma série de carências, em que o medo e a incerteza são motores da inapetência; (3) a experiência de estrangeiridade vivida no exílio ressalta a nostalgia de sabores perdidos. Com este trabalho, percebe-se que as alterações que conflitos políticos geram no espaço social alimentar são estruturantes, apontando a abrangência do fenômeno alimentar em suas dimensões culturais e sociais. Além disso, destaca-se a potência da obra literária como corpus que possui todos os elementos cabíveis a uma análise antropológica e que comporta densa reflexão sobre a condição humana.

Palavras-chave: Segurança Alimentar e Nutricional. Conflito. Cultura. 


\section{Abstract}

This article aims to understand the changes that political conflicts presented in the work Persepolis, used as a corpus of this research, generate in the feeding social space. Because it is an illustrated diary, the kind of comic book of autobiographical character, we used two types of analysis, verbal and of images, which have specific data processing, focusing on passages that address the theme "Feeding" in the scenario of conflicts generated by the Iranian revolution. Verbal data were cut into sequential frames and in them were observed elements of interest for research. As for the visual data, it observed the presence of objects, body and facial expressions of the characters. In both approaches, we sought data in which the theme of Feeding Social Space would be clear. A classification matrix was developed. The analysis returned the following information: (1) in Persepolis scenario there is the production of an epidemic hunger; (2) the conflict imposes on the subjects a series of deficiencies, in which fear and uncertainty are engines of appetite; (3) the strangeness of experience lived in exile underscores the nostalgia of lost flavors. With this work, we can see that the changes that political conflicts generated in the food social space are structural, indicating the scope of the food phenomenon in its cultural and social dimensions. In addition, there is the power of the literary work as a corpus that has all the appropriate elements to an anthropological analysis and comprising dense reflection about the human condition.

Key words: Food Security. Conflict. Culture.

\section{Introdução}

O nome Persépolis refere-se à forma como os gregos denominavam a antiga capital do Império Persa, "Cidade dos Persas" (parseh + polis). ${ }^{1}$ A obra em análise neste trabalho também se chama Persépolis: um diário ilustrado de Marjane Satrapi, iraniana que presenciou a Revolução Islâmica em seu país em 1979, bem como seus desdobramentos durante as décadas de 80 e 90, durante a República Islâmica. O fio condutor da obra éo conflito de Marjani, uma jovem moderna, filha de pais politizados, frente a um país opressor e autoritário.

Marjane Satrapi nasceu em Rasht, no Irã, em 1969. Bisneta de um imperador do país e tendo estudado no liceu francês de Teerã, teve uma educação que combinou a tradição da cultura persa com valores ocidentais e de esquerda. Nascida numa família moderna e politizada de classe média 
alta, em 1979 assistiu ao início da revolução que introduziu o regime xitta no Irã. Vinte e cinco anos depois, Satrapi conta suas experiências em seu diário ilustrado: Persépolis.

Enquanto narra seus conflitos, entremeados de raiva e rebeldia, a autora deixa pistas de como a Revolução Islâmica guiou um processo de grandes transformações no seio da sociedade civil iraniana. Sabe-se que um dos sistemas que mais recebe influência de conflitos e catástrofes ambientais e civilizacionais, como as guerras, é a alimentação. ${ }^{2}$ Um relatório da Organização das Nações Unidas para Alimentação e a Agricultura, no ano de 2014, mostra que apesar dos avanços mundiais com relação à questão da insegurança alimentar, persistem diferenças marcantes entre as regiões. A África Subsaariana e a Ásia Ocidental, por exemplo, são regiões que, por serem afetadas por conflitos, apresentam avanços muito modestos, com altos índices de subalimentação. ${ }^{3}$

Sabe-se, portanto, que a alimentação sofre modificações em tempos de conflitos. Resta aqui perguntar como isso acontece. Essa é uma das questões de interesse para a Antropologia da alimentação, enunciada por Contreras e Gracia: ${ }^{4}$ ela busca compreender e diagnosticar os fenômenos alimentares, descrevendo e interpretando transformações que acontecem e aconteceram, e seu impacto sobre a sociedade de maneira ampla. As regras culinárias abrangem muitas respostas ao problema antropológico único e fundamental, que questiona o comer e a comida. Por trás da variedade, de fato, se esconde uma unidade. ${ }^{5}$

Poulain \& Proença ${ }^{6}$ propõem um instrumento que dá suporte ao estudo dos modelos alimentares no âmbito da Antropologia da alimentação. Denominam-no de espaço social alimentar: "um objeto sociológico total no sentido maussiniano do termo; quer dizer que 'coloca em movimento' [...] a totalidade da sociedade e de suas instituições". Nele destacam seis dimensões: o comestível, a produção alimentar, o culinário, os hábitos de consumo alimentar, a temporalidade e as diferenciações sociais.

Busca-se compreender, portanto, as alterações que conflitos políticos geram no espaço social alimentar apresentado na obra Persépolis. Espera-se que este trabalho possa apontar algumas possibilidades de diálogo entre a Nutrição e as Ciências Sociais, problematizando, ainda, a possibilidade de tomar a obra de arte, neste caso a literatura em quadrinhos, como corpus de pesquisa onde habita uma reflexão sobre a condição humana na sociedade atual. ${ }^{7}$

\section{Metodologia}

\section{Desenho da pesquisa}

Tratou-se de uma pesquisa de análise documental, tipo exploratória, cujo corpus foi a obra Persépolis, Marjane Satrapi. ${ }^{8}$ O critério de seleção da obra foi intencional: levou-se em conta a relevância de seu conteúdo para o tema estudado, pois além de trazer à tona um quadro bem 
definido de conflito político, abordando uma perspectiva sobre temas muitas vezes incompreendidos no Ocidente - como a situação política do Irã e o islamismo ${ }^{9}$-, trata-se de uma obra contemporânea, que auxilia na compreensão da questão em sua articulação com o espírito do tempo.

\section{Documentação dos dados}

Foram empreendidas sete leituras da obra integral, com o objetivo de realizar um reconhecimento inicial do corpus. Primeiramente, foi realizada uma leitura flutuante da obra, ou seja, uma leitura corrida, sem interrupções, a fim de se ter noção do material em sua integralidade. Posteriormente, as demais leituras focaram as seis dimensões do espaço social alimentar consideradas na obra. Em seguida, foi elaborada uma matriz de classificação para apoiar o trabalho de documentação de dados. A construção dessa matriz tomou como ponto de partida as dimensões que delineiam o espaço social alimentar. ${ }^{6}$

Leituras sucessivas da obra foram empreendidas, com o fim de preencher a matriz. Em cada leitura, eram destacados fragmentos que pudessem delinear o espaço social alimentar em questão, bem como os câmbios que a obra deixava entrever, no durante e pós-Revolução Islâmica. Em seguida, os fragmentos foram sendo lançados na matriz.

Nos quadrinhos, observa-se a utilização de dois códigos: o linguístico e o das imagens. Estes podem ser analiticamente separados, mas são complementares para a leitura dos HQs, mesmo que em alguns momentos possa haver predominância de uma ou outra linguagem. ${ }^{10}$ Eisner ${ }^{11}$ reafirma a relevância dos dois códigos no trabalho com HQs.

A configuração geral da revista de quadrinhos apresenta uma sobreposição de palavras e imagem, e, assim, é preciso que o leitor exerça as suas habilidades interpretativas visuais e verbais. As regências da arte (por exemplo, perspectiva, simetria, pincelada) e as regências da literatura (por exemplo, gramática, enredo, sintaxe) superpõem-se mutuamente (p. 8). ${ }^{11}$

Portanto, as possibilidades de narrativa são limitadas quando se trabalha com apenas uma dessas dimensões. ${ }^{12}$ Considerando sua importância (visual e verbal) para o processo de análise, a matriz elaborada contemplou espaços para a documentação de ambos os materiais. Alémdisso, durante o preenchimento da matriz, procedeu-se à identificação dos personagens, sempre que possível, sobretudo na presença de vários diálogos, com ressalva aos monólogos da protagonista, que foram interpretados como pensamentos e sinalizados como tal.

A obra não contém número de páginas. Para facilitar, portanto, a localização dos fragmentos interpostos na matriz, procedeu-se da seguinte maneira: após a indicação do trecho, colocava-se o título da seção do HQ e a página correspondente à referida seção. 


\section{Análise dos dados}

Com a matriz consolidada, o processo de análise foi iniciado. A matriz foi fixada em um lugar visível para o pesquisador, de modo que ele pudesse sempre visualizá-la e, assim, se sentisse mais próximo e familiarizado com os dados a serem lidos.

Conforme jácomentado, a análise em conjunto de desenho e roteiro se faz necessária sempre que esses elementos se completarem para definir o contexto estudado. Todavia, por serem materiais diferentes, texto e imagem necessitaram de tratamentos analíticos específicos.

O material verbal foi analisado segundo a proposta de análise de conteúdo. Bardin, ${ }^{13}$ autora da metodologia, sugere que três fases compõem esse tipo de análise: (1) Pré-análise: fase de realização do primeiro contato com o material feito através da leitura, que foi realizada neste trabalho ainda durante a fase de documentação, conforme descrito anteriormente; (2) exploração do material: momento em que as unidades de análise são elucidadas, bem como enumeração e classificação dos dados em categorias. Nesta fase, foi possível iniciar uma busca por um padrão nos dados, no que diz respeito a uma modelização do espaço social alimentar; e por fim, o (3) tratamento dos dados, inferência e interpretação: fase em que se pretende dar significância aos dados, a partir da produção de quadros, gráficos, diagramas e figuras que objetivem destacar as informações obtidas. Neste último momento, o essencial foi a produção de sínteses que buscavam responder à questão inicial levantada na investigação.

Para análise do material visual, foi utilizada a técnica de análise semiótica de imagens paradas, ${ }^{14}$ que envolveu: (1) a eleição das imagens de interesse para a investigação; (2) a descrição dos elementos presentes nas imagens, observando-se a presença de objetos, expressão facial e corporal dos personagens; (3) a elaboração de uma descrição conotativa, momento no qual a análise pode valer-se de conhecimentos culturais específicos, analogias, associações e comparações. O valor dado à análise das imagens neste trabalho parte do princípio de que o desenho é uma manifestação gráfica elaborada por um ilustrador. Os desenhos são, portanto, muito mais que ícones realistas ou de representação da realidade; são frutos de processo de criação, em que o artista inventa, cria o novo, produzindo assim, obra de arte. ${ }^{15}$

\section{Critério de seleção das imagens e textos}

Foram utilizados imagens e textos de Persépolis que apresentavam cenas ou comentários que se enquadram nas seis dimensões relacionadas ao espaço social alimentar. ${ }^{6}$ 


\section{Resultados e Discussão}

\section{Modelização do espaço social alimentar em Persépolis}

Um modelo alimentar é um conjunto de conhecimentos que agrega múltiplas experiências realizadas sob a forma de acertos e erros pela comunidade humana. Esse modelo se apresenta sob uma série de categorias encaixadas, imbricadas, as quais são cotidianamente utilizadas pelos membros de uma sociedade, sem que os mesmos tenham verdadeiramente consciência, pois tal encadeamento ocorre de maneira implícita. ${ }^{6}$ Assim sendo, a modelização do espaço social alimentar em Persépolis pode ser elaborada da seguinte maneira.

\section{0 comestivel}

Satrapi nos dá uma visão clara do comestível em Persépolis, em um Irã igualmente tradicional e moderno. Durante sua infância, a comida esteve ligada a festividades como em $O$ véu (p. 5), ${ }^{a} \mathrm{em}$ que sua família comemora o Noruz, celebração a Zoroastro, quando se comem maçãs, brotos e pães; ou ligada ao afeto, como quando em Moscou (p. 5), a jovem Satrapi prepara chocolate para seu tio (Anuch). Mesmo diante da guerra, os gêneros alimentícios (apesar de escassos) apresentamse no cotidiano familiar, como em As joias (p. 6), em que, ao fazer compras com sua mãe, Satrapi comenta "Olha, ainda tem feijão vermelho. Dá pra fazer um chili hoje à noite". ${ }^{b}$ No contexto histórico da obra, o conflito nos apresenta limitações no âmbito do comestível, pela diminuição na variedade e quantidade de gêneros alimentícios. Fischler ${ }^{5}$ aponta que a escassez é muitas vezes o motor da neofilia: a falta faz com que nações incorporem ao seu repertório alimentos antes tidos como culturalmente não comestíveis. Contudo, évisto em Persépolis que novos produtos não foram incorporados. O efeito, no caso da família de Marjane, foi no âmbito da diminuição da quantidade, o que já poderia configurar um quadro de insegurança alimentar e nutricional moderado. ${ }^{16}$

a A obra de quadrinho referida não possui números de páginas. Por este motivo, os números referidos nas citações da obra de análise foram feitos considerando o número do capítulo. Portanto, o "p" refere-se ao número do capítulo da obra de análise.

b Destaca-se que no chili, tanto a preparação como a maior parte dos ingredientes que a compõem, tem origem na Mesoamérica. Todavia, com a intensificação das trocas globais potencializadas pela Terceira Revolução Industrial, e com o consequente fenômeno conhecido como McDonalização dos costumes alimentares, muitos pratos foram internacionalizados. O chili é um desses, que apesar de não ter origem iraniana, refere-se hoje a um pertencimento global. Ver mais em: The Cambridge world history of food (Kenneth Kiple e Kriemhild Ornelas) e História da alimentação (Jean-Louis Flandrin e Massimo Montanari). 


\section{A produção alimentar}

Infere-se que a diminuição na quantidade de alimentos na mesa de uma família de condição socioeconômica privilegiada seja fruto da diminuição da produção alimentar no contexto do país. A diminuição da produção de alimentos no contexto da guerra é um cenário habitual no âmbito de conflitos, como pode ser observado na clássica publicação do professor inglês de agricultura Thomas Hudson Middleton (1923). ${ }^{17}$ Todavia, há em Persépolis uma questão singular na qual se destaca a produção alimentar: as bebidas alcoólicas. Com a proibição do consumo de bebidas alcoólicas pelo Estado islâmico, a produção dessas passa a ser feita no âmbito artesanal e de maneira ilegal, como visto em $O$ vinho (p. 4): "meu tio era o fornecedor de vinho. Tinha montado um verdadeiro laboratório de vinificação no porão da casa dele. A dona Nasrin, que trabalhava também pra ele, era quem esmagava as uvas". O aumento do consumo do álcool em cenário de conflitos, como também em contextos de proibição, é relatado por autores como Froud et al., ${ }^{18}$ em estudo sobre os atuais conflitos na Geórgia. Já autores como Wallace \& Roberts ${ }^{19}$ sugerem que o ambiente pós-conflito colabora para o desenvolvimento de políticas conservadoras, como as de restrição de álcool. Essas medidas, segundo Radaev, ${ }^{20}$ podem aquecer o consumo de álcool produzido em âmbito doméstico, como observou no contexto da Rússia.

\section{O culinário}

O culinário em Persépolis aponta para transformações simples e rápidas, ainda que feitas com esmero. As descrições apontam, sobretudo, para as bebidas. Em Esqui (p. 1), o sentimento de compaixão destaca-se através do cuidado na oferta de chá, "Oh, querida! Vocêpassou maus bocados... toma aqui este chazinho." "Suco de laranja, eu mesmo espremi, agorinha.” A simplicidade dos alimentos e das ofertas, nestes casos, não relaciona-se com o simplório. Hásempre um desvelo e cuidado próprios ao saber culinário. Os personagens parecem obedecer àmáxima de Mia Couto, em o Fio das Missangas, que defende que cozinhar éum modo de amar os outros. ${ }^{21}$ Fisher $^{22} \mathrm{em}$ Como cozinhar um lobo, também destaca a importância do zelo no preparo dos alimentos, mesmo no contexto de guerra. Ela, por exemplo, fala da importância de se ferver a água próximo ao tempo de servir o chá, para que esse não tenha saber desagradável de água velha. ${ }^{22}$

\section{Os hábitos de consumo alimentar}

Em Persépolis fica explícita a ligação da personagem com o ambiente familiar: as refeições (a maioria das vezes o jantar) são servidas com todos à mesa, seguidas por discussões normalmente com teor político, como visto em Moscou (p.1): “[...] e eu tinha um herói na família... nem preciso 
dizer que gostei na hora" - mostra Marjane junto à família ouvindo as histórias de seu tio Anuch em seus anos de exílio. A manutenção do rito de comensalidade em tempos de escassez ou de distanciamento do alimento é algo retratado por Medeiros. ${ }^{23} \mathrm{~A}$ comensalidade é "claramente um rito de agregação [...] que foi chamado [de] um 'sacramento de comunhão'”(p. 43). ${ }^{24}$ Outro ponto a ser observado é a diferença nos costumes à mesa entre os ambientes familiar e de exílio, em destaque no capítulo $O$ macarrão (p. 5). Satrapi, já exilada e fora de seu ambiente doméstico, é advertida pela Madre superiora por comer o alimento diretamente da panela. Satrapi justifica sua atitude: "Mas, aqui, todo mundo assiste TV comendo". A Madre retruca: "mas não numa panela! que modos são esses?”. A televisão no contexto da refeição, em um comer solitário fruto da condição de exilada, parece comprometer tanto a sociabilidade como a ritualização alimentar. A relação entre televisão e desrritualização das refeições é apontada por autores como Castro \& Abdala. ${ }^{25}$

\section{A temporalidade}

Satrapi inicia sua história em $O$ véu (p. 1) com a seguinte frase: "Essa sou eu, com 10 anos de idade, em 1980". Ao começar seu relato de forma datada, ela nos prepara para seguir por uma longa jornada que iria de sua infância ao início de sua idade adulta, jornada que se inicia e finda envolta em conflitos de ordem política. Percebe-se, na sua infância, características implícitas a essa fase, como o orgulho pela história de sua nação e energia para questionar tudo de que discorda. Em sua adolescência, destaca-se a rebeldia. Em $O$ cigarro (p. 7), essa fase é descrita: "Quanto a mim, selei meu ato de rebeldia contra a ditadura da minha mãe fumando o cigarro que tinha roubado do meu primo 2 meses antes. Não achei exatamente bom, mas não era hora de entregar os pontos. Agora eu tinha crescido". Ao fim de sua história, mostra uma Marjane Satrapi que, assim como seu país, amadureceu em meio a conflitos. O maior traço temporal que pode ser observado em termos de alimentação refere-se ao cenário Irã-exílio. Observa-se, no período de exílio, a predominância de um aborrecedor comer solitário, ${ }^{26}$ a nostalgia dos alimentos de sua terra, como também o momento de aprendizagem de um novo gosto, o gosto da nova terra. ${ }^{27}$

\section{As diferenciacõoes sociais}

A autora questiona a diferença entre as classes sociais, inicialmente, na infância. Por exemplo, em $O$ véu (p. 4), lê-se: "Porque a empregada não comia na mesa com a gente [...]", e demostra ao longo de toda a obra sua preocupação com as desigualdades. Em outro momento, em A carta (p. 5), ao não entender o por que da empregada não poder namorar o filho do vizinho, indaga ao pai "Ohh! Mas ela não tem culpa de ter nascido onde nasceu? Pai! Você é a favor ou contra as 
classes sociais? Quando entrei no quarto da Mehri, ela estava chorando...a gente não estava na mesma classe social, mas pelo menos estava na mesma cama”. A relação de subordinação entre patrão-empregado não parece ser uma variação que se relaciona diretamente com os conflitos armados. Medeiros, ${ }^{28,29}$ estudando a relação entre patrões e empregados em famílias abastadas percebe, este comportamento de apartar à mesa o diferente.

Satrapi, em toda sua jornada, através de suas memórias, guia o leitor ao seu mundo, onde sua expressão de sociedade está constantemente ligada ao emocional. Sua concepção de comunidade está sempre ligada por laços de afeto. Nesse contexto, a comida tem a função de aliança entre a autora e sua comunidade, tornando o comer um nó que as une em seu meio social.

\section{Comer em tempos de conflito}

\section{A produção de uma fome epidêmica}

A fome, em seus diversos aspectos, apresenta-se em Persépolis como reflexo dos conflitos pessoais da autora e dos conflitos externos. Nestes últimos, podemos enxergar o impacto de confrontos armados sobre a alimentação de uma população.

A fome édefinida como a privação do direito à segurança alimentar e nutricional (SAN). O tipo de fome que se desvela na obra pode ser caracterizada como fome epidêmica. ${ }^{2}$ Nesta, mesmo na certeza de sua temporalidade, não é possível estimar quanto tempo dura a privação. Segundo Josué de Castro, as epidemias de fome não se limitam aos aspectos discretos e toleráveis das fomes parciais, das carências específicas. São epidemias de fome global quantitativas e qualitativas, alcançando com incrível violência os limites extremos da desnutrição e da inanição aguda e atingindo indistintamente a todos, ricos e pobres, fazendeiros abastados e trabalhadores do eitos, homens, mulheres e crianças, todos açoitados de maneira impiedosa pelo terrível flagelo das secas. Este quadro pode ser observado na imagem 1 (A carta [p. 2]).

A fome que vemos em Persépolis não provém da seca ou de catástrofes naturais, e sim das guerras. A região, antigamente chamada Pérsia, conhecida hoje como Irã, teve sua história marcada por conflitos armados e invasões estrangeiras. A fome indistinta descrita por Josué de Castro foi vista por Satrapi e descrita em seu diário ilustrado, mostrando sobretudo o impacto das mudanças no regime político na história da sua família.

Em As Joias (p. 1), a autora mostra seu ponto de vista e exprime, ao descrever, nos diálogos, a relação da guerra sobre a carência alimentar da população. "A guerra começou pra valer", com esta frase junto às prateleiras vazias, observa-se o real significado do conflito. Neste cenário, mesmo as famílias de camadas abastadas são submetidasà escassez e à fome. Segundo Grada, ${ }^{30}$ 
as maiores fomes do século XX foram ligadas a conflito civil e da guerra, em que a ação humana tem efeitos mais deletérios do que ações da natureza, em muitos casos. Destaca-se a importância dos fatores políticos na disponibilidade de alimentos. A ênfase desse panorama é observada na imagem 2 (As Joias [p. 1]).

"É só as lojas ficarem vazias por um dia, que vocês quase se devoram. E se dizem 'gente civilizada' [...]", diz a personagem ao criticar o comportamento da população frente à escassez. A inserção das classes altas, antes alheias à questão da insegurança alimentar e nutricional do país, mostra a extensão com que a fome epidêmica se apresenta. Em Como cozinhar um lobo, Fisher ${ }^{22}$ descreve figurativamente essa situação, ao dizer que "o lobo fincou firmemente uma pata no que parece ser uma rachadura crescente na porta" (p. 89), deixando claro que a fome é uma realidade, apenas potencializada pelo cenário do conflito, e vivida na sua dimensão endêmica pelas pessoas em situação de maior vulnerabilidade social, mesmo em ausência de conflitos.

Esse quadro é comum em países permeados por conflitos armados. Comparando-se dados oficiais, relatórios feitos pela organização Médicos Sem Fronteiras na Líberia mostram uma situação de fome em 30 aldeias ao redor da linha de frente de um grupo de 2.280 crianças menores de cinco anos: $35 \%$ sofriam de kwashiorkor grave. ${ }^{31} \mathrm{O}$ mesmo documento também mostra que a guerra é o principal fator que leva à instalação da fome epidêmica nos países em conflitos, e que os embargos à ajuda internacional colaboram para o agravo do quadro. ${ }^{31}$

Se a fome e a insegurança com o futuro atingem as classes sociais altas durante a guerra, as camadas de baixa renda sofrem com as mazelas do conflito com antecipação. Mesmo antes da guerra declarada, famílias pobres eram torturadas pela falta de alimento durante as revoluções.

Por meio da súplica dos pais de Mehri, "temos filhos demais, senhor! Com ela, são 14 ou 15" [...] "Na casa de vocês ela vai comer bem", épossível observar a dimensão de iniquidade social instaurada pela conflito: em virtude do quadro de fome, os pais de Mehri são obrigados a entregar sua filha para adoção. Já não tinham condição de sustentá-la. A insegurança alimentar e nutricional, entre esses sujeitos em condição socioeconômica já comprometida antes do conflito, é grave: a fome atinge as crianças, ${ }^{16}$ como visto na imagem 3 (As Joias [p. 1]).

Um detalhe importante a destacar: neste cenário de escassez, a promessa religiosa de uma nova ordem ganha relevo. No capítulo $A$ chave (p. 7), imagem 4, a obra nos apresenta os contornos da guerra e Satrapi cita uma passagem da infância, quando presencia a agonia de Dona Nasrin, que relata o medo de perder o filho para a guerra: "Disseram pra ele que no paraíso tem comida à vontade, mulheres, casas de ouro e diamante". As promessas vinculadas à propaganda de guerra, especialmente as que se referem ao paraíso islâmico, são recompensa pela morte na guerra religiosa e justificam um presente recoberto de fome e miséria. ${ }^{32}$ 
Vislumbrar um futuro ou mesmo uma recompensa são os principais motivos que levam ao alistamento dos jovens soldados, muitas vezes em fuga de uma situação de miséria. Tática semelhante, evidentemente com a promessa de um paraíso cristão, foi utilizada durante a Guerra do Paraguai, quando crianças, em sua maioria meninos de rua, se expuseram à morte em combate. Sob o ponto de vista do jovem soldado, em grande parte recrutas inexperientes, pobres, despreparados, transformados em guerreiros e que sozinhos tiveram que lutar por sua sobrevivência, a falta de opções era a principal motivação. A fome, durante o período de guerra, ajuda a compor o pano de fundo essencial para a compreensão da experiência do soldado. ${ }^{33}$

Tratando-se de um diário ilustrado, Persépolis expõe suas experiências, trazendo em nuances aspectos que retratam a fome epidêmica como colateral do conflito - por muitas vezes esquecido ou mascarado pelas perdas em combate.

\section{As faltas impostas pelo conflito: 0 medo e a incerteza como motores da inapetência}

Em Persépolis, é possível ver a ligação da autora com sua obra. Não somente pela expressão de suas singularidades (a autobiografia presente no diário), mas, sobretudo, por sua experiência coletiva enquanto iraniana, momento em que preenche as condições de um agenciamento coletivo de enunciação: "o que ele diz já constitui uma ação comum, e o que ele diz ou faz, é necessariamente político, ainda que os outros não estejam de acordo"(p. 39). ${ }^{34}$

Barthes ${ }^{35}$ concorda com esta perspectiva deleuziana do agenciamento coletivo de enunciação: o autor ao produzir uma obra, se desloca de si e passa a vivenciar o outro, produz um enunciado que não é individual, mas pautado em um cenário coletivo e político. Satrapi, ao trazer à tona sua experiência singular, produz, ao mesmo tempo, uma enunciação coletiva de desespero de todo um país advindo da guerra, de mulheres assoladas por um ideal machista, de um povo que sentia fome, um povo que sofria com medo. As marcas do conflito são observadas principalmente em seus desenhos.

Como visto no recorte a seguir (imagem 5), por exemplo, é possível perceber tais marcas pela forma abatida como são retratados os personagens. A apatia reflete o sentimento do povo e o medo iminente da perda: fosse pela prisão ou pela morte. "Então a gente ficou horas esperando... o silêncio era igual ao de antes de uma tempestade", a espera referida no diálogo muitas vezes era incerta, esperava-se por notícias sem saber se essas seriam boas ou más. "A literatura tem descrito há centenas de anos a noção de trauma e as reações psicológicas a situações traumáticas”, como por exemplo, conflitos armados (p. 4). ${ }^{36}$ 
Esse sentimento de vacuidade também é retratado na obra de Marcel Proust, Em busca do tempo perdido, que localiza parte da sua narrativa no período da Primeira Guerra Mundial. A guerra traz à tona miséria, sangue, conflitos. A guerra transformou a proustiana Combray em um campo de batalha, sua igreja, seus vitrais todos destruídos. Portanto, além das faltas materiais, de fisiologia digestiva, o regime de carências apresentado na obra produz literatura: "A dor nos servirá de incentivo. A imaginação e o pensamento serão máquinas em si mesmas admiráveis, mas podem ficar inertes. E o sofrimento as põe em movimento"(p. 254). ${ }^{37}$

Marjane, igualmente, produz como resultado dessa dor, obra de arte. O desejo de dar razão a esses signos da vacuidade trazidos à tona pela guerra ficam evidentes nas expressões melancólicas de seus personagens, bem como na mudança em seus cenários: com tons mais escuros e poucos objetos de decoração (capítulo As ovelhas, imagens 6 e 7). Quanto aos alimentos, percebe-se uma preponderância das bebidas (chá ou vinho) frente às comidas, como pode ser visto, por exemplo, na imagem 6 , As ovelhas (p. 1).

A obra reveste-se, portanto, de dois tipos de escassez: a de alimentos e a de Sentido. A busca por Sentido refere-se à desconstrução dos signos trazidos pela guerra; envolve uma busca com o fim de desfazer o emaranhado de forças que há em seu redor, um movimento para inventar novas possibilidades de vida. Na busca por este Sentido, Deleuze \& Guattari ${ }^{38}$ mostram que a boca, que encontra sua territorialidade primitiva nos alimentos (órgão dos sentidos), desterritorializa-se, jejua e busca reterritorializar-se em torno de um Sentido (órgão de Sentido).

Satrapi projeta a melancolia e a inapetência de seus traços, descrevendo em seus desenhos o que sua boca guarda: a tristeza de seu povo e os pavores da guerra. Isso pode ser percebido na imagem 8, As ovelhas (p. 6): mesmo não sabendo da origem, o distanciamento do tio (Anuch) trouxe a Satrapi um sentimento de inapetência vindo do desgosto pela partida e do medo pelo real motivo de sua ida.

Assim sendo, como nos mostra Medeiros: ${ }^{29}$

[...] a guerra é mais um dos eventos que obriga o homem a voltar seu olhar abaixo do perímetro ocular e a perceber o que se passa ao seu redor, voltar-se à Terra: "onde é que a Terra vai buscar esta comida"? Ricos e pobres, soldados e cocotes, burgueses, povo e aristocracia: não há Deus. Os alimentos faltam, os ricos racionam, o povo chega à miséria (p. 76).

Essa é a mensagem que Satrapi deixa em Persépolis: as faltas impostas pelo conflito transcendem as faltas materiais de alimentos e produzem até mesmo a inapetência, onde as dores produzidas pelo conflito se transformam em motores de uma busca por Sentido. 


\section{Saudades do Irã e o gosto do exílio}

Persépolis possui, em sua narrativa, o tom romântico ao falar do Irã. Satrapi busca contar para o mundo ocidental como é a vida no Irã e tropeça em si mesma e em seus fragmentos de identidade para recompô-los em um livro que, como ela mesma diz, étambém uma posição diante da vida.

A saudade do Irã não conota exclusivamente as lembranças marcantes, mas reporta à ideia de Amon \& Menasche, ${ }^{39}$ de que é na comida de todo dia, através dos rituais de preparo, ingredientes habituais e os temperos, que sentidos antigos podem ser negociados e novos sentidos são absorvidos. É no cotidiano que podemos notar a fluidez de fronteiras no contorno de uma comunidade. Foi na ausência de sua antiga rotina que Satrapi veio a incorporar novas formas de ver o comer, construindo uma apreciação da nostalgia pelos sabores de sua terra.

Exatamente como a linguagem, a cozinha contém e expressa a cultura de quem a pratica, é depositária das tradições e das identidades de grupo. Constitui, assim, um extraordinário veículo de autorrepresentação e de comunicação: não apenas é instrumento de identidade cultural, mas talvez seja o primeiro modo para entrar em contato com cultuas diversas (p. 21). ${ }^{40}$

Montanari ${ }^{40}$ defende a comida como veículo de autorrepresentação e de troca cultural como, possivelmente, mais forte do que o idioma. Uma experiência de exílio, além de comprometer o componente da sociabilidade, conforme comentado, contribui para negociar sabores de sua tradição, o que movimenta o sentimento de nostalgia e a incorporação de novos sabores, o que pode imputar ao sujeito os sentidos de um novo pertencimento, como mostra Montanari, uma forma de entrar em contato com o diferente. Satrapi corrobora essas afirmativas ao descrever seu primeiro contato com a cultura europeia, ao conhecer Lucia, sua companheira de quarto austríaca, como pode ser observado na imagem $9, A$ sopa (p. 8).

Nessa imagem, a troca de alimentos, como pistaches para Satrapi e sopa de cogumelos para Lucia, fala um pouco sobre suas origens e modos de existir em relação à alimentação: "Dei a ela uns pistaches que eu tinha trazido [...]. É uma especialidade do país, nos damos de presente quando alguém viaja para o exterior". Bem mais do que a palavra, a comida auxilia na intermediação entre culturas diferentes, abrindo os sistemas culinários a todas as formas de invenções, cruzamentos e contaminações. ${ }^{40}$ "A Lucia, por sua vez, fez uma sopa de Knorr para mim. Creme de cogumelos".

Não só Montanari, mas estudiosos como Lévi-Strauss ${ }^{41}$, Roland Barthes ${ }^{42}$ e Mary Douglas ${ }^{43}$ partiram de uma analogia da comida com o sistema linguístico, indagando-se sobre as convenções e regras que regem os modos como os itens de comida, concebidos como signos em um sistema, são categorizados e combinados. ${ }^{40}$ A comida é concebida como manifestação de uma estrutura subjacente, que pode ser apreendida, conduzindo ao conhecimento de características de uma sociedade. ${ }^{39}$ Assim 
como se aprende um idioma, é possível aprender um gosto. E é assim que Marjane caminha em sua aprendizagem como exilada, como demonstrado na imagem 10, A pílula (p. 2).

Satrapi expõe o estereótipo europeu já existente de um signo da cultura árabe em seu diálogo com Armelle: "Claro, como eu sou boba, o chá, a Índia, a Pérsia, a Rússia, o Samovar...” - a associação do chá às especiarias vindas de países do Oriente. Se por um lado vive essas experiências que misturam estereótipos e preconceitos, tão comuns à visão do Ocidente sobre o Oriente, ${ }^{44,45}$ Satrapi busca a memória de seu país por meio de conhecidos no cenário do exílio, como no caso de Armelle. O contato com o povo iraniano fez com que Armelle compreendesse o sentimento de Satrapi em relação a sua nação - o que pode ser percebido na Imagem 11, A pílula (p. 2).

Outro momento crucial para amainar as penas da saudade do exílio era o contato com a comida de sua terra preparada pelas mãos de sua mãe: "Passei 27 dias ao lado dela. Saboreei, a comida celestial do meu país, preparada pela minha mãe. Era bem diferente de macarrão". Nesse cenário, a comida passa a representar um veículo para manifestar significados, emoções, visões de mundo, identidades, bem como um modo de transformar, pela resolução de conflitos, realização de mudanças, desistências. A comida da mãe ganha destaque nesse contexto, como acontece na experiência de muitos exilados. ${ }^{46}$

Como sugerem Amon \& Menasche, a comida coloca em relevo seu potencial para abordar temas como tradição, etnia, harmonia, discordância, transitoriedade, identidade. Sobre a questão da memória ativada pela saudade, em específico, $\operatorname{Sutton}^{47}$ defende que a memória sobre a comida é uma forma de consciência histórica, tornando assim a expressão da dualidade, cultural e temporal, de Satrapi, vinda de sua origem iraniana e suas experiências com culturas diversas no cenário do exílio. A imagem 12, O Cavalo (p. 9), pode demonstrar claramente o exposto acima.

\section{Conclusões}

Por meio de Persépolis, Satrapi nos mostra seu olhar sobre os conflitos que vivenciou. Confundindo-se constantemente com sua obra, ela apresenta um pouco sobre a alimentação nesses cenários de crise.

Quanto ao comestível, apresenta um quadro de insegurança alimentar e nutricional moderado, que pode ser denominado como "fome epidêmica". A redução da quantidade de alimentos, todavia, acontecia em um grau que não implicava inserção de alimentos outrora não comestíveis do ponto de vista cultural; e quanto à produção de alimentos, observou-se diminuição da produção alimentar no contexto do país e início da produção em âmbito doméstico e ilegal de bebidas alcoólicas. No terreno do culinário, as transformações tendem a ser mais simples e rápidas, mas o zelo no preparo dos alimentos permanece; no âmbito da partilha, percebe-se a manutenção 
dos ritos de comensalidade no contexto da escassez, mas o comer solitário, fruto da condição de exilada, parece comprometer tanto a sociabilidade como a ritualização alimentar. E na questão da temporalidade, somem-se ao comer solitário, os dois outros aspectos da condição de exilada: a nostalgia dos alimentos de sua terra e aprendizagem de um novo gosto. E por fim, diferenciações sociais próprias do conflito não foram observadas.

Assim sendo, o universo de Satrapi trouxe à tona elementos ímpares para o estudo de um espaço social alimentar. Suas principais alterações no que diz respeito ao tempo de conflitos, portanto, parecem ser a escassez de alimentos, a ativação de um regime de medo e insegurança que alimenta a inapetência e um aprendizado de uma nova vivência mais solitária e plural durante o exílio.

A obra possui importantes discussões de caráter político sobre questões orientais, vistas pelo Ocidente apenas como "rápidas manchetes" e desprovidas de sua significância. A guerra e, especialmente, a fome mostrada por Persépolis, são vistas de forma muito mais próxima a nós. Além, é claro, da questão da discriminação de gênero e de etnia.

Os HQs têm o potencial de comunicar suscitando curiosidade e interesse pela leitura. Neste caso, ele abriu portas para o conhecimento de uma narrativa que interconecta cultura, alimentação e conflitos. Acredita-se que esta possa ser não apenas uma via para realizar pesquisas que correlacionem a área da Nutrição com as Ciências Sociais e Humanas, com o fim de compreender a condição humana em relação ao fenômeno alimentar. Mas que, ainda, possa atender ao chamado atual que aponta na direção do desenvolvimento de ações de promoção da alimentação saudável no ambiente escolar. A leitura de HQs como ponto de partida para discussões desta natureza pode auxiliar a reflexão junto a estudantes sobre a alimentação: quem somos quando comemos? O que comemos? O que somos quando não comemos? Dentre outras questões...

\section{Referências}

1. Apolinário DFR. Persépolis: Desterritorialização e identidades no Irã de Marjane Satrapi. Revista Litteris 2011; 7.

2. Castro J. Geografia da fome. O dilema brasileiro: pão ou aço. 5. ed. Rio de Janeiro: Civilização brasileira; 2006.

3. Food and Agriculture Organization of the United Nations. O estado da insegurança alimentar no mundo [Internet]. Roma: FAO; 2014. Disponível em: http://www.fao.org/news/story/pt/ item/243923/icode/

4. Contreras J, Gracia, M. Alimentação, sociedade e cultura. Rio de Janeiro: Editora Fiocruz; 2011.

5. Fischler C. El (h)omnívoro: el gusto, la cocina y el cuerpo. Barcelona: Editorial Anagrama; 1995.

6. Poulain JP, Proença RPC. Reflexões metodológicas para o estudo das práticas alimentares. Revista de Nutrição 2003; 16(4):365-386. 
7. Morin E. A cabeça bem-feita: repensar a reforma, reformar o pensamento. 8. ed. Rio de Janeiro: Bertrand Brasil; 2003.

8. Satrapi M. Persépolis. São Paulo: Companhia das Letras; 2007.

9. Marra L. Tradição e transgressão em Persépolis, de Marjane Satrapi. Nau Literária: Crítica e Teoria de Literatura 2014; 10(1):20-35.

10. Silva NM. Elementos para a análise das histórias em quadrinhos. In: XXIV Congresso Brasileiro da Comunicação; set. 2001; Campo Grande, MS. Campo Grande INTERCOM - Sociedade Brasileira de Estudos Interdisciplinares da Comunicação; 2001. p. 1-15.

11. Eisner W. Quadrinhos e arte sequencial. São Paulo: Martins Fontes; 1989.

12. Langie C. Desvendando os quadrinhos. Revista ORSON 2011; 1:310-312.

13. Bardin L. Análise de conteúdo. Lisboa: Persona; 1977.

14. Penn G. Análise semiótica de imagens paradas. In: Bauer MW, Gaskell G. Pesquisa qualitativa com texto, imagem e som: um manual prático. Petrópolis: Vozes; 2003.

15. D’Avila PA. Análise dos princípios do processo de design da pintura de Peter Paul Rubens: o caso da obra "o rapto das filhas de leucipo" [dissertação]. Porto Alegre: UniRitter Programa de pósgraduação em Design; 2012.

16. Burlandy L, Salles-Costa R. Segurança alimentar e nutricional: concepções e desenhos de investigação. In: Kac G, Schieri R, Gigante DP, organizadores. Epidemiologia nutricional. Rio de Janeiro: Editora Fiocruz / Atheneu; 2007. p. 485-502.

17. Middleton TH. Food production in war. Londres: Clarendon Press; 1923.

18. Froud R, Abel G. Using ROC curves to choose minimally important change thresholds when sensitivity and specificity are valued equally: the forgotten lesson of Pythagoras. Theoretical considerations and an example application of change in health status. Journal Plos One 2014; 9(12):e114468.

19. Wallace K, Roberts B. An exploration of the alcohol policy environment in post-conflict countries. Journals Oxford University Press 2013; 49(3): 356-362.

20. Radaev V. Impact of a new alcohol policy on homemade alcohol consumption and sales in Russia. Alcohol Alcohol 2015; 50(3):365-372.

21. Couto M. O Fio das missangas. São Paulo: Companhia das Letras; 2009.

22. Fisher MFK. Como cozinhar um lobo. São Paulo: Companhia das Letras; 1998.

23. Medeiros M. Comensalidade: um rito de socialização vencido pela fome? [monografia]. Natal: Universidade Federal do Rio Grande do Norte; 2009.

24. Van Gennep A. Os ritos de passagem. Petrópolis: Vozes; 1977.

25. Castro LA, Abdala MC. Televisão no momento das refeições. Revista Horizonte Científico [Internet] 2011; 5(2). Disponível em: http://www.seer.ufu.br/index.php/horizontecientifico/article/view/6249

26. Pelbart PP. Images of time in Deleuze; Naked life, dumb life, a life; how to live alone. Academic Journal 2014; 8(1): 111-140. 
27. Bielous SD. As pisadas do exílio através do enredo das narrativas. Antíteses 2010; 3(5):513-28.

28. Medeiros MCS. Eça de Queiroz e a cozinha burguesa: literatura e alimentação [dissertação]. Natal: Universidade Federal do Rio Grande do Norte; 2012.

29. Medeiros MCS. Marcel Proust para além das madeleines. uma culinária indócil. [tese]. Natal: Programa de pós-graduação em Ciências Sociais; 2014.

30. Grada CO. Famine: a short history. Princeton: Princeton University Press; 2009.

31. Godlee F. Thousands starving in Liberia's civil war. BMY 1993; 307:85.

32. Pierucci AF. Máquina de guerra religiosa: o islãvisto por weber. Novos Estudos CEBRAP 2002; 62:73-96.

33. Dourado MTG. A história esquecida da guerra do paraguai: fome, doenças e penalidades [tese]. São paulo: USP Programa de Pós-Graduação em História Social, 2010.

34. Deleuze G, Guattari F. Kafka: para uma literatura menor. Rio de Janeiro: Imago; 1975.

35. Barthes R. Roland Barthes por Roland Barthes. Barcelona: Editorial Kairos; 1978.

36. Oliveira SM. Traumas Da Guerra: Traumatização secundária das famílias dos ex-combatentes da guerra colonial com PTSD [dissertação]. Lisboa: Universidade de Lisboa; 2008.

37. Proust M. O tempo redescoberto. São Paulo: Editora Globo; 2013.

38. Deleuze G, Guattari F. Proust e os signos. Rio de Janeiro: Forense Universitária; 2003.

39. Amon D, Menasche R. Comida como narrativada memória social. Sociedade e Cultura 2008; 11(1):13-21.

40. Montanari M. O mundo na cozinha: história, identidade e trocas. São Paulo: Estação da Liberdade SENAC; 2009.

41. Lévi-Strauss C. A origem dos modos àmesa. São Paulo: Cosac Naify; 2006.

42. Barthes R. Le message photographique. Communications 1961; 1(1):127-138.

43. Douglas M. In the active voice. New York: Routledge; 1982.

44. Guedes JV, Dias L, Sousa R. A mídia ocidental e os povos árabes: uma relação de preconceito e generalizações. In: XIII Congresso de Ciências da Comunicação na Região Centro-Oeste; 2011; Cuiabá.

45. Marin M. Cuisine d’orient, cuisine d’occident. Médiévales 1997; 16(33):9-21.

46. Chagas J. Beiral de exílio, saudades e afagos. Revista Anuário de Literatura 2007; 12:119-126.

47. Sutton DE. Remembrance of repasts: an anthropology of food and memory. New York: Bloomsbury Academic; 2001. 
